\title{
Inpatient Treatment of Headache: An Evidence-Based Assessment
}

\author{
Frederick G. Freitag, DO; Al Lake, III, PhD; Richard Lipton, MD; Roger Cady, MD; \\ on behalf of the US Headache Guidelines Consortium, Section on Inpatient Treatment \\ Chairpersons: Seymour Diamond, MD; Stephen Silberstein, MD
}

Objective.-To evaluate inpatient treatment of headache in the United States.
Participants.-
Evidence.-
Conclusions.-

Key words:

Abbreviations: $\mathrm{CH}$ chronic headache, FHs frequent headaches, CDH chronic daily headache, TM transformed migraine, CM chronic migraine, CTTH chronic tension-type headache, MOH medication overuse headache

(Headache 2004;44:342-360)

The treatment of headache is commonly delivered in an outpatient environment. There are patients who are refractive to outpatient treatment, and in whom inpatient care may be appropriate. Factors that determine the optimal setting, methods, and results of such treatment have come under increasing scrutiny secondary to the cost of inpatient care. The US Headache Guidelines Consortium project, in conjunction with the National Headache Foundation, believed that the need existed to objectively examine the issues surrounding inpatient treatment.

The epidemiology of chronic headache $(\mathrm{CH})$ is important to understand in this context, since essentially all patients that are treated in the hospital have highfrequency headache often associated with significant disability. This severity of illness produces significant

From the Diamond Headache Clinic, Chicago and Finch University of Health Sciences, Chicago Medical School, North Chicago (Drs. Freitag and Diamond), Ill; Midwestern University, Chicago College of Osteopathic Medicine, Downers Grove, Ill (Dr. Freitag); Michigan Headache and Neurological Institute, Ann Arbor, Mich (Dr. Lake); Albert Einstein College of Medicine of Yeshiva University, Bronx, New York, NY (Dr. Lipton); Headache Care Center, Springfield, Mo (Dr. Cady); and Thomas Jefferson University and Headache Center, Philadelphia, Pa (Dr. Silberstein).

A conflict of interest for hospitalization of patients with headache may exist for the following authors of this article: Frederick G. Freitag, DO; Al Lake, III, PhD; and Seymour Diamond, MD, since all currently are affiliated with a dedicated inpatient treatment program for headache. Dr. Stephen Silberstein has written several articles on inpatient treatment of headache and formerly ran an inpatient program. Of the participants in the conference leading to this article, the following attendees hospitalized patients, maintained an inpatient program at the time, or had been previously affiliated with an inpatient treatment program: $R$. Michael Gallagher, DO; Ninan Mathew, MD; Joel Saper, MD; and Alan Rapoport, MD.

A complete list of the members of the US Headache Guidelines Consortium, Section on Inpatient Treatment appears at the end of this article.

Address all correspondence to Dr. Frederick G. Freitag, Diamond Headache Clinic, Suite 500, 467 West Deming Place, Chicago, IL 60614.

Accepted for publication December 4, 2003. 
health care costs, and is responsible for a major impact on businesses and the economy.

Methods of treating headache in the hospital can follow several paths, based on the accessibility of resources. While there exist these differing paths of treatment, only treatment in a dedicated headache unit has been investigated in depth in the United States. Reports from other countries that do not have dedicated inpatient treatment lend support to other options for the treatment of headache. Some have suggested that inpatient treatment is not required, even in recidivist patients, and limited reports have examined aggressive outpatient treatment as an option in headache management.

None of the studies reported to date provide class I evidence for efficacy, either as an inpatient or an outpatient. Recommendations are made to assess treatment of patients with high-frequency headache to garner better scientific evidence for differing treatment approaches.

A meeting organized under the auspices of the US Headache Guidelines Consortium was held on April 9, 1999 in New York City to evaluate inpatient treatment of headache in the United States. Current treatment criteria for inpatient care, survey data of the potential role of treatment, and outcomes data were presented and discussed. From this meeting emerged a mission statement: "There are patients with frequent, intractable headache who do not benefit from traditional outpatient care. Based upon a review of the existing data, many individuals appear to benefit from advanced and intense levels of care, including inpatient treatment."

In this article, we review the epidemiology and economic impact of $\mathrm{CH}$, criteria for inpatient treatment, components of inpatient care, and outcomes of treatment, and provide a consensus statement and recommendations for further research to address the role of inpatient treatment of headache.

\section{EPIDEMIOLOGY OF CHRONIC HEADACHE}

Frequent headaches, defined by an attack frequency of $\geq 180$ headache days per year, comprise a heterogeneous group of headache disorders. ${ }^{1-7}$ These are commonly divided into 2 subtypes. Firstly, headaches that typically last $<4$ hours. These include chronic cluster headache $(\mathrm{CCH})$, chronic paroxysmal hemicrania, and hypnic headache. The term chronic daily headache $(\mathrm{CDH})$ is usually reserved for those who have frequent headache that typically lasts for $>4$ hours. Chronic daily headache includes 4 major primary headache disorders: transformed migraine (TM) or chronic migraine (CM), chronic tension-type headache (CTTH), hemicrania continua, and new daily persistent headache. ${ }^{1-5,8}$ This group of primary headaches is a leading reason for consultation in headache centers in the United States, accounting for $30 \%$ to $75 \%$ of all subspecialty visits. ${ }^{1,7,9,10}$ In most clinic-based studies, most patients with $\mathrm{FH}$ fall into the $\mathrm{CM}$ category, usually in association with medication overuse. ${ }^{4,5,11-13}$ Risk factors for CM include analgesic, triptan, and ergot overuse; depression; insomnia; and head injury, as well as stressful or traumatic life events. ${ }^{7,9-15}$ Clinic-based studies demonstrate that these disorders impose an enormous burden on individuals with headache and on society. ${ }^{8}$

Not only do risk factors, such as depression, play a role in migraine and daily headache, but by themselves represent an issue of comorbidity in migraineurs. Breslau found that migraineurs are 3 times as likely to experience major depression as those without migraine, 6 times more likely to have a panic disorder, and over 5 times as likely to have generalized anxiety, an obsessive-compulsive disorder, or a bipolar disorder. ${ }^{16}$ Furthermore, individuals with comorbid lifetime depression and migraine have a 10- to 17.5-fold increased risk of attempting suicide as compared with the general population (not affected by depression or migraine). These comorbid disorders have a compounding effect on the impact and lost productivity headache imparts in the workplace. ${ }^{17}$ Many medical conditions can complicate the treatment of headaches. In a study conducted at a managed care organization, patients with migraine generated nearly twice as many medical claims in comparison with other group patients, and their pharmacy claims were almost 2.5 times that of other groups. ${ }^{18}$ These comorbid medical issues may impact the treatments available for headache, and, conversely, the treatments necessary for headache may have an impact on the optimal management of the 
comorbid medical condition. Since CM develops from migraine, these comorbid disorders are a major problem in $\mathrm{CDH}$.

A study by Scher et al, using a population-based survey, examined the prevalence of CTTH, CM, and frequent headache of other types (FH/O). ${ }^{19}$ Prevalence by headache type and sex is summarized in Table 1. The 1-year prevalence for all FHs was $4.1 \%$; CTTH, 2.2\%; CM, 1.3\%; and FH/O, 0.6\%. Overall prevalence of $\mathrm{FH}$ was $5.0 \%$ among women and $2.8 \%$ among men (female to male ratio, 1.8:1). The female to male sex ratio varied by $\mathrm{FH}$ subtype from 2.4 for $\mathrm{CM}$ to 2.3 for migraine to 1.6 for $\mathrm{CTTH}$ and $\mathrm{FH} / \mathrm{O}$.
Similarities in symptomatology, sex distribution, and prevalence data suggest that migraine is tied to FH with migrainous features.

Median age of the group with FH was 39 years in both men and women and did not vary by FH subtype. Prevalence for all headache subtypes appeared to be higher in the 40s and 50s and dropped to the lowest levels after aged 55. Prevalence of TM appeared to drop off more rapidly after aged 55 than did the prevalence of CTTH.

African Americans have a lower prevalence rate than Caucasians (Table 1). There was an inverse relationship between prevalence of $\mathrm{CH}$ and education. Age, race, and education were associated with one

Table 1.-Crude Prevalence (CP) and Adjusted Prevalence Ratios (APR) of Frequent Headache by Demographic Characteristics in Females and Males*

\begin{tabular}{|c|c|c|c|c|c|c|c|c|c|}
\hline \multirow[b]{2}{*}{ Feature } & \multirow[b]{2}{*}{ No. of Subjects } & \multicolumn{2}{|c|}{$\begin{array}{c}\text { Frequent } \\
\text { Headache (All) }\end{array}$} & \multicolumn{2}{|c|}{$\begin{array}{l}\text { Chronic Tension- } \\
\text { type Headache }\end{array}$} & \multicolumn{2}{|c|}{$\begin{array}{l}\text { Chronic } \\
\text { Migraine }\end{array}$} & \multicolumn{2}{|c|}{$\begin{array}{c}\text { Frequent } \\
\text { Headache/Other }\end{array}$} \\
\hline & & $\mathrm{CP}, \%$ & $\mathrm{APR} \dagger$ & $\mathrm{CP}, \%$ & APR & $\mathrm{CP}, \%$ & APR & $\mathrm{CP}, \%$ & APR \\
\hline Females & 7767 & 5.0 & - & 2.6 & - & 1.7 & - & 0.8 & - \\
\hline \multicolumn{10}{|l|}{ Race } \\
\hline Caucasian & 5506 & 5.4 & 1.00 & 2.7 & 1.00 & 1.8 & 1.00 & 0.9 & 1.00 \\
\hline African American & 1874 & 4.0 & $0.72 \ddagger$ & 2.2 & 0.80 & 1.3 & 0.71 & 0.4 & 0.47 \\
\hline Other & 241 & 5.0 & 0.64 & 3.3 & 1.09 & 0.8 & 0.32 & 0.8 & - \\
\hline Unknown & 79 & & & & & & & & \\
\hline \multicolumn{10}{|l|}{ Education } \\
\hline$<12$ th grade & 461 & 9.3 & $2.24 \S$ & 3.9 & 1.59 & 4.6 & $3.25 \S$ & 0.9 & 2.93 \\
\hline Completed high school & 2439 & 4.4 & 1.00 & 2.5 & 1.00 & 1.4 & 1.00 & 0.4 & 1.00 \\
\hline Post high school & 1994 & 5.0 & 1.14 & 2.6 & 1.05 & 1.5 & 0.98 & 1.1 & $2.32 \ddagger$ \\
\hline College degree & 1656 & 5.3 & 1.15 & 2.5 & 0.99 & 1.8 & 1.12 & 1.2 & 2.16 \\
\hline Postgraduate & 986 & 4.0 & 0.83 & 2.3 & 0.88 & 1.2 & 0.80 & 0.4 & 0.70 \\
\hline Unknown & 65 & & & & & & & & \\
\hline Males & 5089 & 2.8 & - & 1.6 & - & 0.7 & - & 0.5 & - \\
\hline \multicolumn{10}{|l|}{ Race } \\
\hline Caucasian & 3876 & 3.0 & 1.00 & 1.7 & 1.00 & 0.8 & 1.00 & 0.5 & 1.00 \\
\hline African American & 952 & 1.9 & $0.58 \ddagger$ & 1.1 & 0.66 & 0.3 & 0.39 & 0.5 & 0.63 \\
\hline Other & 179 & 3.4 & 1.19 & 1.1 & 0.48 & 1.7 & $3.83 \ddagger$ & 0.6 & - \\
\hline Unknown & 56 & & & & & & & & \\
\hline \multicolumn{10}{|l|}{ Education } \\
\hline$<12$ th grade & 344 & 4.1 & 1.57 & 1.7 & 1.27 & 1.2 & 2.06 & 1.2 & 1.76 \\
\hline Completed high school & 1461 & 2.8 & 1.00 & 1.2 & 1.00 & 0.8 & 1.00 & 0.8 & 1.00 \\
\hline Post high school & 1182 & 3.5 & 1.19 & 2.0 & 1.58 & 1.0 & 1.27 & 0.4 & 0.52 \\
\hline College degree & 1207 & 2.1 & 0.61 & 1.5 & 0.99 & 0.4 & 0.42 & 0.2 & $0.20 \ddagger$ \\
\hline Postgraduate & 744 & 2.2 & 0.61 & 1.6 & 1.05 & 0.4 & 0.44 & 0.1 & 0.15 \\
\hline Unknown & 58 & & & & & & & & \\
\hline
\end{tabular}

${ }^{*}$ Data from Scher et al. ${ }^{19}$

$\dagger$ Prevalence ratio adjusted for age, race, and education.

$\ddagger P<.05$.

$\S P<.001$. 
another; a Poisson regression was used to adjust for these confounding variables.

\section{HEADACHE FEATURES, DISABILITY, DIRECT AND INDIRECT COSTS}

Prevalence of migraine peaks in the third and fourth decades of life, and slightly later for those with CM. This significantly adds to the economic burden of this disease, since its greatest impact occurs during potentially productive years of a person's career and thus, the burden is experienced by the patient and employer. There is a significant gender bias in the prevalence and disability of migraine. The National Health Interview Survey reported that the prevalence of migraine in women was only 2.5 times that of men, but women in the work force (outside the home) experienced almost 7 times the number of restricted activity days as their male counterparts. ${ }^{20}$ If housewives are included, female migraineurs experience 21 times more restricted activity days than male migraineurs. This suggests that some women may compensate for migraine by choosing careers at home, which may limit the employment pool.

The study by Scher et al found that the overall distribution of headache frequencies was similar for each category of FH (Table 2). ${ }^{19}$ Thirty-seven percent of those with $\mathrm{FH}$ experienced headache every day. In comparison with the other forms of $\mathrm{FH}, \mathrm{CM}$ was associated with attacks of longer duration, work or school missed more frequently, and higher levels of reduced efficiency at work. Subjects with $\mathrm{CM}$ were more likely to report ever having consulted a doctor for headache ( $83 \%$ of women, $54 \%$ of men) than subjects with CTTH (52\% of women, $40 \%$ of men). These estimates are comparable to other published reports. $^{5,21-25}$

Many studies have demonstrated the impact of migraine in the workplace. $\mathrm{Hu}$ and colleagues estimated that over $93 \%$ of the economic impact of migraine ( $\$ 13$ billion in 1999) was attributable to absenteeism from work and reduced productivity. ${ }^{26}$ In a migraine clinical trial population, Osterhaus et al estimated that $76 \%$ to $86 \%$ of the total cost of migraine was due to lost labor cost, amounting to between \$2088 and \$4128 per migraineur annually in $1992 .{ }^{27}$ In a 1999 study of managed care subjects, Fishman and Black estimated that migraine was associated with mean annual indirect costs of $\$ 4548$ in men and $\$ 4897$ in women. ${ }^{28}$

Despite significant advances in migraine-specific pharmacologic treatments, as well as the increasing attention to effective nonpharmacologic therapies, there remains a group of people with intractable headache who fail at outpatient treatment. ${ }^{29}$ In a longitudinal study of patients with headache in a primary care setting, Von Korff and colleagues found that $60 \%$ of the patients had continued disability at 1 year, with $20 \%$ continuing with significant pain and disability at 2 years. ${ }^{30}$ These patients with intractable headache not only experience an unremitting personal burden of migraine, but contribute disproportionately to the economic burden borne by society. A minority of migraineurs contributes the major share of the direct cost of treatment and medical utilization - those with high-frequency severe headaches in combination with comorbid illness. ${ }^{18}$ This disproportional contribution from the severely affected minority also holds true for indirect costs. For example, only $20 \%$ of a populationbased sample accounted for $77 \%$ of the lost workdays due to migraine, and $40 \%$ accounted for $75 \%$ of the lost workday equivalents due to reduced work effectiveness. ${ }^{31}$

The direct costs of headache care have been examined. In one study, patients in primary care cost $87 \%$ more to care for than similarly matched patients without headache. ${ }^{32}$ A review in 2000 showed that hospitalizations for migraine have a mean length of stay of 5.1 days and a mean cost of $\$ 6908 .^{33}$ These migraine-specific costs are only a portion of the overall direct medical costs of caring for patients with migraine. Migraine-associated comorbidities also add to medical care costs. Migraineurs generated twice the psychiatric claims as matched controls, with a monthly medical claim of $\$ 186$ versus $\$ 112$. Overall, the direct medical costs attributable to migraine are small relative to the indirect costs. Effects of comorbid illness were demonstrated in a study by Villareal who compared patients from a major headache center who were hospitalized for headache treatment with those who were not hospitalized; those who required hospital treatment had significantly higher levels of anxiety, depression (as measured both by the Beck Depression Inventory and the Zung Self-rating Scale), 
Table 2.-Distribution of Selected Headache Characteristics Between Migraineurs and Patients With Frequent Headache*

\begin{tabular}{|c|c|c|c|c|c|c|c|c|}
\hline \multirow[b]{2}{*}{ Variable } & \multirow[b]{2}{*}{$\begin{array}{l}\text { Migraine } \dagger \\
(\mathrm{n}=1357)\end{array}$} & \multicolumn{3}{|c|}{$\begin{array}{c}\text { Females } \\
\text { Frequent Headache }\end{array}$} & \multirow[b]{2}{*}{$\begin{array}{c}\text { Migraine } \dagger \\
(\mathrm{n}=393)\end{array}$} & \multicolumn{3}{|c|}{$\begin{array}{c}\text { Males } \\
\text { Frequent Headache }\end{array}$} \\
\hline & & $\begin{array}{l}\text { Chronic } \\
\text { Tension-type } \\
\text { Headache } \\
(\mathrm{n}=208)\end{array}$ & $\begin{array}{l}\text { Chronic } \\
\text { Migraine } \\
(n=129)\end{array}$ & $\begin{array}{c}\text { Frequent } \\
\text { Headache/ } \\
\text { Other } \\
(\mathrm{n}=61)\end{array}$ & & $\begin{array}{l}\text { Chronic } \\
\text { Tension-type } \\
\text { Headache } \\
(\mathrm{n}=81)\end{array}$ & $\begin{array}{l}\text { Chronic } \\
\text { Migraine } \\
(\mathrm{n}=35)\end{array}$ & $\begin{array}{c}\text { Frequent } \\
\text { Headache/ } \\
\text { Other } \\
(\mathrm{n}=27)\end{array}$ \\
\hline \multicolumn{9}{|c|}{ Attack frequency, No. (per week) $\ddagger$} \\
\hline $1-51(<1)$ & 70.6 & - & - & - & 76.0 & - & - & - \\
\hline $52-101(1+)$ & 17.8 & - & - & - & 13.4 & - & - & - \\
\hline $102-153(2+)$ & 7.1 & - & - & - & 6.2 & - & - & - \\
\hline $154-259(3-4)$ & 4.4 & 37.1 & 37.8 & 44.8 & 4.4 & 34.2 & 45.7 & 46.2 \\
\hline $260-363(5-6)$ & - & 25.7 & 22.8 & 20.7 & - & 26.6 & 14.3 & 15.4 \\
\hline $364+(7+)$ & - & 37.1 & 39.4 & 34.5 & - & 39.2 & 40.0 & 38.5 \\
\hline \multicolumn{9}{|l|}{ Pain intensity $\S$} \\
\hline $0-4$ & 3.2 & 25.7 & 19.7 & 12.1 & 5.3 & 29.1 & 8.6 & 30.8 \\
\hline $5-6$ & 14.8 & 37.1 & 26.8 & 25.9 & 17.3 & 43.0 & 20.0 & 19.2 \\
\hline $7-8$ & 39.7 & 29.2 & 23.6 & 46.6 & 45.6 & 20.3 & 40.0 & 19.2 \\
\hline $9-10$ & 42.4 & 7.9 & 29.9 & 15.5 & 31.8 & 7.6 & 31.4 & 30.8 \\
\hline Unilateral pain $\|$ & 69.4 & 41.7 & 61.1 & 42.6 & 62.6 & 42.5 & 66.7 & 56.5 \\
\hline Pulsatile pain $\|$ & 86.8 & 43.5 & 69.1 & 66.0 & 85.0 & 43.2 & 77.1 & 50.0 \\
\hline Exacerbation on movement $\|$ & 60.8 & 13.2 & 48.4 & 39.2 & 61.8 & 9.1 & 73.5 & 37.5 \\
\hline Nausea $\|$ & 76.5 & 12.6 & 46.8 & 27.8 & 62.1 & 6.3 & 51.4 & 21.7 \\
\hline Vomiting $\|$ & 39.5 & 0.0 & 14.6 & 20.0 & 33.9 & 0.0 & 21.4 & 0.0 \\
\hline Photophobia\| & 89.0 & 23.3 & 62.1 & 58.2 & 87.5 & 31.2 & 80.0 & 50.0 \\
\hline Phonophobia\| & 85.8 & 32.3 & 62.1 & 82.1 & 80.4 & 23.3 & 77.1 & 52.2 \\
\hline \multicolumn{9}{|l|}{ Duration, h } \\
\hline$<12$ & 24.6 & 61.3 & 40.7 & 66.7 & 45.6 & 76.4 & 52.2 & 62.5 \\
\hline $12-23$ & 4.6 & 2.8 & 7.4 & 13.3 & 7.0 & 1.8 & 8.7 & 6.3 \\
\hline $24-48$ & 27.3 & 26.1 & 35.8 & 8.9 & 28.2 & 20.0 & 21.7 & 25.0 \\
\hline$>48$ & 43.5 & 9.9 & 16.1 & 11.1 & 19.3 & 1.8 & 17.4 & 6.3 \\
\hline \multicolumn{9}{|c|}{ How often do you miss work or school for all or part of the day? } \\
\hline Never/rarely & 64.0 & 92.5 & 77.0 & 92.7 & 73.2 & 93.6 & 82.9 & 80.8 \\
\hline$<$ Half the time & 15.9 & 3.5 & 9.5 & 3.6 & 11.5 & 3.9 & 5.7 & 3.9 \\
\hline$\geq$ Half the time & 20.1 & 4.0 & 13.5 & 3.6 & 15.3 & 2.6 & 11.4 & 15.4 \\
\hline \multicolumn{9}{|l|}{ Reduced work efficiency, \% } \\
\hline None & 9.0 & 34.4 & 15.3 & 11.5 & 11.1 & 46.6 & 9.7 & 18.2 \\
\hline$<25$ & 22.1 & 39.4 & 37.8 & 42.3 & 20.7 & 26.0 & 41.9 & 45.5 \\
\hline $25-49$ & 34.9 & 16.6 & 30.6 & 32.7 & 37.9 & 20.6 & 29.0 & 27.3 \\
\hline $50-74$ & 17.1 & 6.9 & 9.0 & 7.7 & 13.8 & 2.7 & 6.5 & 4.6 \\
\hline $75+$ & 16.9 & 2.9 & 7.2 & 5.8 & 16.5 & 4.1 & 12.9 & 4.4 \\
\hline
\end{tabular}

*Data from Scher et al. ${ }^{19}$ Values are percentages.

$\dagger$ Limited to those migraineurs with $<180$ headaches of any type per year.

$\ddagger$ No. of days per year with migraine (for the migraine column) or any type of headache (for the frequent headache columns).

$\S$ For those respondents with $>1$ headache type, the headache characteristics refer to migraine (for the migraine column) or the more frequent type (for the frequent headache columns).

॥More than rarely.

more severe pain, and a higher frequency of analgesic use. $^{34}$

\section{INPATIENT TREATMENT}

Admission Criteria.- Inpatient headache treatment occurs in 2 different hospital environments: community/regional hospitals and specialty headache treatment units. A recent survey was conducted in 174 physicians with an interest in headache selected from the membership of the American Headache Society (American Association for the Study of Headache at the time of the study). Over $50 \%$ used inpatient 
Table 3.-Results of Survey of Physicians Interested in Inpatient Treatment of Headache and Available Admission Criteria From Insurance Companies

\begin{tabular}{|c|c|c|}
\hline Reason for Admission & $\begin{array}{c}\text { No. }(\%) \text { of } \\
\text { Physicians } \\
(\mathrm{N}=21)\end{array}$ & $\begin{array}{c}\text { No. }(\%) \text { of } \\
\text { Insurance } \\
\text { Companies } \\
(\mathrm{N}=7)\end{array}$ \\
\hline Change in headache pattern & $3(14.2)$ & $1(14.3)$ \\
\hline Organic disease & $5(23.8)$ & $5(71.5)$ \\
\hline $\begin{array}{l}\text { Clinically significant nausea and } \\
\text { vomiting }\end{array}$ & $5(23.8)$ & $5(71.5)$ \\
\hline Frequent parenteral medications & $1(4.7)$ & $0(0.0)$ \\
\hline Complicated migraine & $1(4.7)$ & $1(14.3)$ \\
\hline Status migraine & $8(38.0)$ & $3(42.9)$ \\
\hline $\begin{array}{l}\text { Patient at risk from triptan use or } \\
\text { other observation needed }\end{array}$ & $2(9.4)$ & $0(0.0)$ \\
\hline Failed acute therapy & $2(9.4)$ & $0(0.0)$ \\
\hline Failed outpatient D.H.E. 45 & $1(4.7)$ & $0(0.0)$ \\
\hline Severe drug allergies & $1(4.7)$ & $0(0.0)$ \\
\hline $\begin{array}{l}\text { Medication overuse headache/drug } \\
\text { dependency }\end{array}$ & $12(57.0)$ & $4(57.2)$ \\
\hline Failed prophylaxis & $7(33.3)$ & $0(0.0)$ \\
\hline Failed outpatient treatment & $0(0.0)$ & $6(85.8)$ \\
\hline Copharmacy management issues & $1(4.7)$ & $0(0.0)$ \\
\hline Prolonged pain state & $4(18.8)$ & $0(0.0)$ \\
\hline Chronic daily headache & $6(28.5)$ & $0(0.0)$ \\
\hline $\begin{array}{l}\text { Comorbid medical and/or psychiatric } \\
\text { disease }\end{array}$ & $8(38.0)$ & $3(42.9)$ \\
\hline Disability & $4(19.0)$ & $1(14.3)$ \\
\hline Intractable cluster headaches & $3(14.1)$ & $0(0.0)$ \\
\hline Trauma related, acute or chronic & $1(4.7)$ & $1(14.3)^{*}$ \\
\hline Distance & $1(4.7)$ & $0(0.0)$ \\
\hline Comprehensive treatment program & $1(4.7)$ & $0(0.0)$ \\
\hline Refer for admit elsewhere & $5(23.8)$ & $0(0.0)$ \\
\hline No interest or no guidelines & $2(9.4)$ & $0(0.0)$ \\
\hline
\end{tabular}

*With loss of consciousness only.

hospitalization on at least some occasions for detoxification from opioids, barbiturates, or prescription analgesics in patients with headache. ${ }^{35}$

A second survey (Table 3) was undertaken of a selection of physicians with a special interest in headache. This included 5 physicians, who had dedicated inpatient treatment programs of varying size and complexity, as well as 10 community-based physicians and 6 university-based physicians, who did not have inpatient programs. Of these 21 physicians, 19 had criteria they used for admitting patients, or were interested in obtaining criteria. One of the 2 physicians not interested in criteria was a community-based physician who no longer even attempted the process because of the high managed care penetration in his area; the second was a university-based physician who did not believe in treatment guidelines in general. Attempts were also made to obtain specific criteria from insurance industry utilization review organizations for inpatient hospitalization of headache. This data was available from only 7 insurance companies.

Though this survey relied upon a convenience sample, clinicians and the insurance industry had a surprisingly convergence of interests and criteria given the high profile of cost containment. Criteria from inpatient programs substantially overlapped in their admission criteria guidelines, as did the criteria of community- and university-based physicians who did not have inpatient programs.

Previously, there had been 2 sets of published criteria for admission to headache treatment centers (Tables 4 and 5). ${ }^{36}$ The historic background to these

\section{Table 4.-Admission Criteria of Michigan Headache and Neurological Institute for Inpatient Headache Treatment Program at Chelsea Hospital*}

- Presence of moderate to severe intractable headache that fails to respond to appropriate and aggressive outpatient or emergency department measures and requires repetitive sustained parenteral treatment (eg, DHE)

- Presence of continuing nausea, vomiting, or diarrhea

- Need to detoxify and treat toxicity, dependency, or rebound phenomena and/or monitor protectively against withdrawal symptoms, including seizures, in cases in which this cannot be achieved effectively or safely on an outpatient basis

- Presence of dehydration, electrolyte imbalance, and prostration that requires monitoring and intravenous fluids

- Presence of unstable vital signs

- Presence of repeated previous emergency department treatments

- Likely presence of serious disease (eg, subarachnoid hemorrhage, intracranial infection, cerebral ischemia, severe hypertension)

- Need to rapidly develop both immediate pain reduction and an effective pharmacologic prophylaxis in order to sustain improvement achieved by parenteral therapy (aggressive daily drug manipulation, requiring careful monitoring and drug level evaluation)

- Need to urgently address other comorbid conditions contributing to or accompanying the headache, including medical and/or psychological illness

- Presence of concurrent medical and/or psychological illnesses requiring careful monitoring in high-risk situations

${ }^{*}$ Adapted from Saper et al. ${ }^{36}$ 
Table 5.-Admission Criteria of the National Headache Foundation for Treatment of Headache*

- Severe dehydration, for which inpatient parenteral therapy may be necessary

- Diagnostic suspicion (confirmed by appropriate diagnostic testing) of organic etiology, such as an infectious disorder involving the central nervous system (eg, brain abscess, meningitis), acute vascular compromise (eg, aneurysm, subarachnoid hemorrhage), structural disorder with accompanying symptoms (eg, brain tumor)

- Prolonged unrelenting headache with associated symptoms, such as nausea and vomiting, which, if allowed to continue, would pose a further threat to the patient's welfare

- Status migraine or dependence on analgesics, ergots, opiates, barbiturates, or tranquilizers

- Pain that is accompanied by serious adverse reactions or complications from therapy-continued use of such therapy aggravates or induces further illness

- Pain that occurs in the presence of significant medical disease, but appropriate treatment of headache symptoms aggravates or induces further illness

- Failed outpatient detoxification, for which inpatient pain and psychiatric management may be necessary

- Intractable and chronic cluster headache, for which inpatient administration of histamine or dihydroergotamine (DHE) may be necessary

- Treatment requiring copharmacy with drugs that may cause a drug interaction, thus necessitating careful observation (eg, monoamine oxidase inhibitors and beta-blockers)

*Adapted from Freitag and Cady. ${ }^{37}$

criteria has certainly contributed to the criteria found in the survey and utilized today.

Treatment.-Inpatient care differs depending on the type of facility and the nature of the headache. Although community-based inpatient treatment, regional or university centers, and dedicated headache inpatient treatment centers may all share the common elements of intravenous protocols and 24-hour nursing care, significant differences exist in the level and sophistication of other aspects of medical management, the diversity and coordination of multidisciplinary services, and the intractability of the patient population. Other factors that influence both the need for hospitalization and the type of care rendered include: medical stability of the patient, presence of coexisting medical illness, medication overuse headache $(\mathrm{MOH})$ or drug dependency issues, psychological and psychiatric comorbidities, and need for patient monitoring during administration of medical therapies.
We do not know if one specific treatment environment for inpatient care is more successful than another. Efforts to compare one treatment setting with another must include a careful comparison of patient populations. The patient population in published outcome studies of specialized headache treatment centers predominantly includes patients who have failed other treatments, which in many cases have included more limited previous inpatient protocols. ${ }^{38,39}$ Evidence exists that patients with $\mathrm{MOH}$, using small amounts of agents, treated on an outpatient basis, may have outcomes as good as those with inpatient careno clear guidelines exist for the patient with $\mathrm{MOH}$. Dedicated inpatient programs, however, suggest that patients with highly complex headache problems associated with significant $\mathrm{MOH}$ and medical and psychological comorbidities are more likely to need treatment in multidisciplinary treatment environments (Table 6). ${ }^{40}$

It may be necessary to hospitalize a patient when severe headache is associated with significant changes in vital signs or clinical condition, such as repetitive vomiting. Repetitive intravenous DHE used $>2$ days has been recognized by the American Academy of Neurology in their practice parameter as necessitating inpatient monitoring. ${ }^{41}$

Overuse of acute treatments for migraine and its associated pain (eg, analgesics, alone or combined with caffeine; sympathomimetics; barbiturates; opiates; triptans; ergots) is a major problem. The IHS

Table 6.-Typical Treatment Modalities in a Multidisciplinary Inpatient Headache Treatment Program
Detoxification
Pharmacologic therapy
Nursing intervention
Physical therapy
Dietary management and education
Stress management
Exercise programs
Biofeedback and relaxation therapy
Cognitive-behavioral treatment
Group psychotherapy
Individual and family psychotherapy
Family groups
Interactions between patients
Lifestyle management
Discharge planning 
guidelines for drug dependency headache are in final stages of revision..$^{42}$ This part of the classification will be replaced by $\mathrm{MOH}$.

Treatment of $\mathrm{MOH}$ is crucial, since preventive therapy often does not work. It may take as long as 12 weeks to reverse the effects of medication overuse. ${ }^{43}$ Failure to achieve successful detoxification as an outpatient occurs in over $50 \%$ of patients due to increased pain during the initial period of withdrawal, and acute withdrawal symptoms in cases of high levels of analgesic use, including butalbital and opioid use, can occur. Even when withdrawal could be managed safely in an outpatient setting, patients have a fear of pain, which interferes with successful withdrawal. Techniques, such as the use of clonidine for opiate withdrawal, ${ }^{44}$ may be of benefit in the outpatient arena. Phenobarbital can be used for withdrawal of short-acting barbiturates. ${ }^{45}$ This requires at least a short-term hospital stay for observation and dose titration.

Management of the patient with $\mathrm{MOH}$ requires acute and preventive therapies for the underlying headache, as well as symptom management related to the withdrawal of the agent producing rebound. The intravenous use of diverse agents including antidopaminergics, muscle relaxants, nonopioid analgesics, and valproic acid may be required to provide interim control of headaches while initiating treatment with preventive medications.

Significant complications of withdrawal of opiates, benzodiazepines, and barbiturates may occur. Observation of patient with close medical monitoring may be required in the first several days of withdrawal of these agents.

Some patients with CCHs do not respond to standard methods of treatment. Adjunctive therapies such as intravenous DHE or IV histamine, which are rendered on an ongoing basis over the course of days to a week, have proven effective in leading to improved treatment outcomes.

Rapid transitions in medical therapies are sometimes initiated to reduce the length of hospitalization and to gain control of the patient's headaches. One example is the patient who needs to undergo a rapid transition from selective serotonin reuptake inhibitor antidepressants to monoamine oxidase inhibitor types, or the reverse. Product labeling specifies that in almost all of these cases, a drug-free interval of 10 to 14 days is required before starting the new agent. This is not a practical solution for patients who suffer profound disabling headaches, and a more rapid transition with a shorter evaluation period should be initiated. Generally, this type of transition has proven safe for most patients, although on occasion this type of therapy may be potentially dangerous. Warning signs include the serotonin syndrome with elevated temperature, agitation, and other serotonergic indications. If left untreated, a potentially morbid situation could occur. Careful observation of these patients during this transition period is essential.

Chronic pain, including headache, may be significantly aggravated by psychological problems. Longterm follow-up research has found that patients with multiple psychiatric diagnoses have a more negative long-term prognosis than patients with little or no psychiatric disturbance. ${ }^{46}$ Accurate diagnosis by qualified psychologists and psychiatrists is essential if development of a long-term treatment program is indicated. Treatment for the patient with $\mathrm{CH}$ attempts to identify specific components of suffering and pain behaviors. Specific psychological intervention occurs on 2 levels. Group therapy sessions, such as assertiveness training, are conducted with a focus on problems common to patients with headache. If indicated, individual psychological counseling is also initiated during the first few days of hospitalization, and continued, as necessary, during and after hospitalization. Intractable headache has a significant impact on family functioning, ${ }^{47}$ and both individual family and family group intervention is often an important part of the program. Patients with refractory headache usually have psychological issues affecting their ability to respond to treatment. In many patients, the headache process is obscured by personality characteristics, coexisting depression, or other major psychiatric conditions including personality disorders. After an initial assessment and basic psychological intervention, it is imperative to establish a pain management program to help these patients deal with the varied aspects of their condition.

Education of the patient with headache, provided by physicians, psychologists, pharmacists, and dietitians, is essential in enhancing the patient's 
understanding of the headache problem and ensuring a successful treatment program. Family members also are encouraged to be involved in the program.

Outcome Studies.-There is no class I evidence for inpatient treatment. Table 7 presents the methods of studies arranged in order of the year of publication. ${ }^{48-74}$ These studies are divided into 3 groups: full reports on patients with $\mathrm{CDH}$, reports based on abstracts only, and reports focusing on posttraumatic headaches only. Most of the outcome research involves intractable $\mathrm{CDH}$. Often analgesic, abortive rebound, or overuse headache was also present. Treatment programs typically involved supervised detoxification, IV therapies (of which D.H.E. 45 was the most common), and prophylactic medications. Studies that made no mention of nonpharmacologic treatment were classified as pharmacologic only.

Most US studies have psychological components including group classes, biofeedback, psychotherapy, and physical therapy. These programs are classified as multidisciplinary. Mean length of stay ranged from 4 to 14 days. Designation of a study as prospective was based on whether the report appeared to indicate the consistent use of some type of structured prehospitalization measure of headache activity that was used as a baseline for posttreatment comparisons.

Interpretation of results is complicated by the variation in patient population, interpretation, and outcome measurement used. The populations of treated patients' comorbid disorders and treatment plans may vary considerably from one program to another, making direct comparisons difficult; while reports may define the patient population as "intractable" or "outpatient treatment failures," and some include the number of years of headache as well as history of CDH. Tertiary national referral centers may tend to see the largest population of patients with previously intractable headache.

Variation in outcome information across studies also makes direct comparison difficult. Some studies compared attack frequency or functional status before and after admission, and others used poorly defined descriptors of improvement such as "significant" or "good to excellent." When available, the percentage of patients with at least a $50 \%$ improvement provides the most comparable measure for comparisons.
Most reports describe as an outcome measure patient-reported headache, withdrawal symptoms, and extent of analgesic/abortive use or misuse after discharge. Some studies show very significant improvements in health care utilization, functional performance at work and home, sleep disturbance, and psychological functioning (eg, depression).

Tables 8 and 9 provide a meta-analysis of the outcome data for inpatient headache treatment from published articles and abstracts. Studies of posttraumatic headache are few and highly variable in response; they were, therefore, not included in the Table. The average (mean and median) percentage of patients with at least $50 \%$ improvement at short-term ( $<6$ months) and long-term ( $>6$ months) follow-up is the most widely available evidence.

The proportion of patients with $50 \%$ improvement was $81 \%$ with short-term and $60.5 \%$ with long-term follow-up. Although not all patients respond, those who do appear to have remarkably stable results over time.

\section{ARE THERE OUTPATIENT ALTERNATIVES TO INPATIENT TREATMENT?}

As an alternative to inpatient treatment, some have proposed the use of intravenous DHE on an outpatient basis. Robbins and Remmes report a prospective outcome study of 35 patients with refractory intractable daily headaches and frequent severe migraine treated with outpatient repetitive DHE. ${ }^{75}$ Daily headache calendars were used as the source of data. Twenty-eight of 35 patients had an excellent response, with either complete resolution of headache or only a mild residual headache. At 6 weeks, 23 (66\%) of 35 sustained at least a $50 \%$ improvement in either frequency or severity of headache. In addition, they report a retrospective chart review of 62 patients with chronic daily muscle contraction-type headaches and severe migraines occurring at least once per week. Eighty-eight percent of 62 patients had an excellent response at the end of the treatment protocol. At 6 weeks, however, only $24 \%$ (10 of 42) sustained an excellent response. They also noted fewer side effects than typically reported in inpatient protocol. ${ }^{76}$

Drucker and Tepper reported a study of sumatriptan $25 \mathrm{mg} 3$ times a day for up to 10 days as a means 


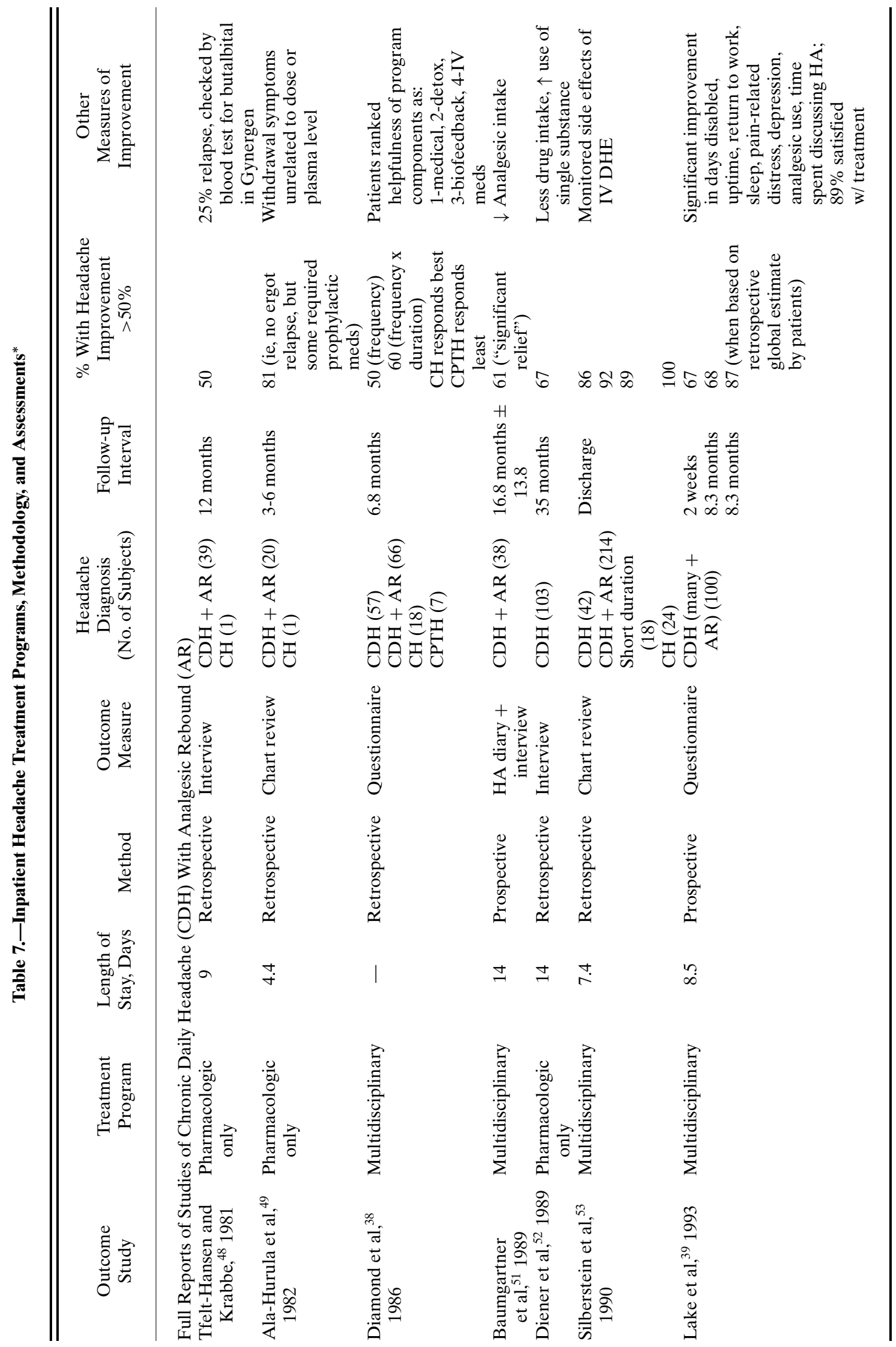









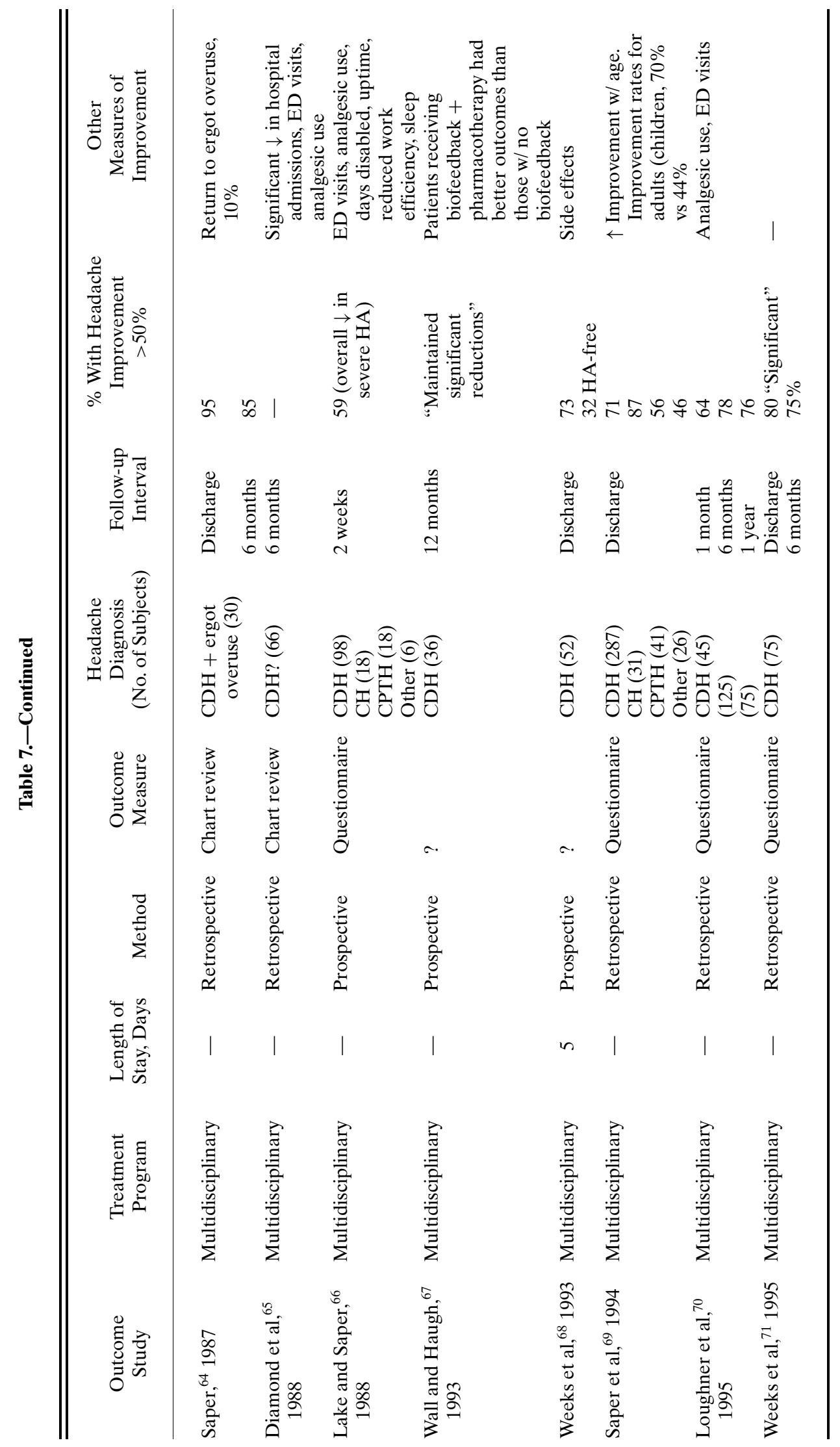




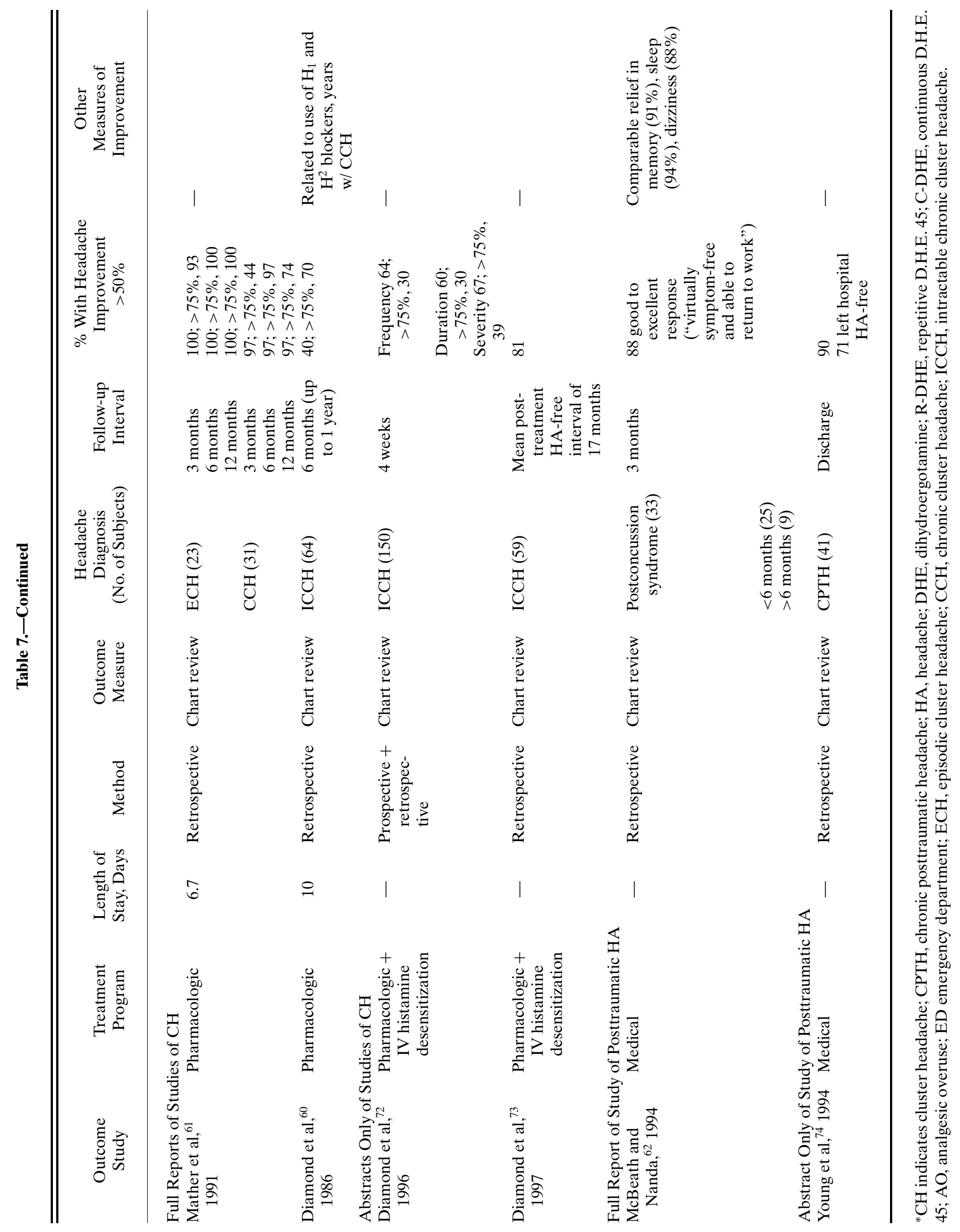


Table 8.-Meta-analysis of Short- and Long-term Outcomes for Inpatient Headache Treatment: Percentage of Patients With Significant $(>\mathbf{5 0} \%)$ Headache Improvement

\begin{tabular}{lcc}
\hline \hline \multicolumn{1}{c}{ Statistic } & $<6$ Months & $>6$ Months \\
& & \\
\hline & & \\
Median & 81.0 & 60.5 \\
Mean & 77.7 & 60.5 \\
Standard deviation & 11.0 & 7.9 \\
Weighted mean & 81.0 & 62.5 \\
Range & $62-91$ & $80-71$ \\
No. of studies & 7 & 528 \\
No. of patients & 561 & \\
& & \\
\hline
\end{tabular}

of assisting outpatients with withdrawal who were analgesic dependent. Patients also received concomitant prophylactic medication. The study found that $58 \%$ of the 27 patients who started were no longer having CDHs at 1 month. ${ }^{77}$

Suhr et al published a comparison of inpatient or "stationary" $(\mathrm{n}=147)$ and outpatient or "ambulatory" $(\mathrm{n}=110)$ drug withdrawal therapy for patients who were overusing analgesic/abortive medication. ${ }^{78}$ Patients were randomly assigned to treatments on a prospective basis. "Only patients with a discontinuation of chronic headache after withdrawal therapy" (ie, successful patients) were recontacted at a mean of 5.9 years (SD, 4.0) after drug withdrawal. Longterm outcome was based on follow-up data from a mailed questionnaire, personal examination, or telephone interview with 60 of the former inpatients and 41 of the outpatients. Regardless of the withdrawal

Table 9.-Meta-analysis of Short- and Long-term Outcomes for Inpatient Headache Treatment: Percentage of Patients With Significant ( $>50 \%$ ) Headache Improvement by Diagnosis

\begin{tabular}{|c|c|c|c|c|}
\hline \multirow[b]{2}{*}{ Statistic } & \multicolumn{2}{|c|}{$\begin{array}{c}\text { Chronic } \\
\text { Daily Headache } \\
\text { (Analgesic Rebound) }\end{array}$} & \multicolumn{2}{|c|}{$\begin{array}{l}\text { Chronic } \\
\text { Cluster } \\
\text { Headache }\end{array}$} \\
\hline & $<6$ Months & $>6$ Months & $<6$ Months & $>6$ Months \\
\hline Median & 72.5 & 67.0 & 97.0 & 81.0 \\
\hline Mean & 73.9 & 64.9 & 89.6 & 80.4 \\
\hline $\begin{array}{l}\text { Standard } \\
\text { deviation }\end{array}$ & 12.8 & 15.8 & 15.3 & 19.1 \\
\hline Range & $51-95$ & $27-87$ & $64-100$ & $54-100$ \\
\hline $\begin{array}{l}\text { No. of } \\
\text { patients }\end{array}$ & 14 & 17 & 5 & 5 \\
\hline
\end{tabular}

strategy, headache improvement in this selected group remained at about $50 \%$ at almost 6 years after completing withdrawal. There was a trend toward a higher rate of analgesic relapse in the patients who were hospitalized (25\%) than in the outpatients (15\%).

A 4-month study by Pini et al compared outcomes for patients with analgesic $\mathrm{MOH}$ treated in a day hospital $(n=73)$ versus an outpatient setting $(n=29) .{ }^{79}$ Based on headache diary measures, both treatments led to significant headache improvement. Contrary to the findings of Suhr et al, however, they found a significantly higher rate of relapse in those treated on an outpatient basis.

Casaly et al found, based on a disability tool, that inpatient treatment was less likely to provide benefit than outpatient treatment. ${ }^{80}$ Inpatient and outpatient groups, however, were not comparable: $56 \%$ of the inpatients met the criteria for analgesic abuse, compared with $28 \%$ of those receiving outpatient therapies $(P<.0008)$. Patients receiving inpatient treatment were also more likely to have $\mathrm{CDH}$. The single outcome measure, scores on the Henry Ford Hospital Disability Inventory, would not have been expected to be a useful outcome assessment modality since it only measures the disability associated with a single headache, and not the range or numbers of disabling headaches experienced by these types of patients.

One of the authors, Lake, and his Colleagues, has found that outcomes at discharge have remained remarkably stable; the severity of illness in admitted patients has increased significantly. In 1992, during the period of data collection for the published study, patients averaged 6.5 days of headache per week on admission. In 1997-1998, patients continued to average 6.6 days of headache per week, but the mean frequency of severe headaches had increased from 3.13 per week (SD, 2.06) to 4.91 (SD, 2.03), an increase from roughly 3 to 5 days of severe to incapacitating headache per week.

The use of an inpatient pain specialty assessment and treatment unit may result in improved long-term results as compared with alternative treatment programs. Williams et al demonstrated, in a recent controlled clinical trial, that those patients treated initially on an inpatient basis had greater improvement in their pain, were able to maintain control of the pain more effectively over 1 year, and utilized overall health 
care services less than those patients matched for type, severity, and duration of pain treated as outpatients. ${ }^{81}$

\section{MULTIDISCIPLINARY VERSUS PHARMACOLOGIC TREATMENT ONLY}

Hoodin and others found that behavioral intervention (group sessions, relaxation tapes at the bedside, intensive individual cognitive-behavioral therapy, and family involvement) was associated with significantly increased adherence to relaxation practice, use of relaxation as a coping skill to manage stress and headache flares, aerobic exercise, healthy sleep behavior, and dietary recommendations over low baseline levels. ${ }^{82}$ Patients who practiced relaxation more frequently - as a coping skill during severe headache and as a preventive measure at other timeshad higher Beck depression scores on admission and showed the greatest decrease in Beck scores at discharge. Overall, the change in Beck scores was significantly correlated with the frequency of relaxation practice. While patients also showed the expected significant reductions in severe headache activity, there was no significant correlation between changes in Beck scores and the amount of severe headache reduction. Published abstracts of multidisciplinary inpatient treatment have reported better outcomes in patients receiving medical intervention plus biofeedback than for medical treatment alone, ${ }^{67}$ and high ratings of helpfulness for the behavioral components of treatment. ${ }^{63}$ A recently reported, prospective, long-term, outcome report relying on headache diary data found significantly less headaches and analgesic use 3 years after discharge in patients who received biofeedback, in addition to inpatient drug withdrawal and prophylactic medication, when compared with those patients who received inpatient medical treatment, but no behavioral intervention. ${ }^{83}$

\section{CONSENSUS STATEMENT}

There is a need for inpatient headache treatment, and appropriately selected patients benefit over both the short and long term. Overall, the results indicate very positive improvements in patients following discharge from inpatient care in centers both here and abroad, with outcomes generally maintained over follow-up periods from 2 weeks to 5 years.

\section{AREAS FOR FURTHER RESEARCH}

A variety of areas require exploration through ongoing research to answer many of the questions raised by the current information that is available. These areas include:

1. Better definition of the patient characteristics that warrant inpatient treatment, predict failure of optimal outpatient management and success with inpatient care

a. Headache diagnosis, symptoms profile, and treatment history

b. Presence of comorbid medical conditions

c. Presence of comorbid psychiatric conditions, including axis II personality disorders

d. Presence of medication misuse/abuse (multisourcing, illegal prescriptions, and recreational use) versus naïve analgesic rebound with their doctor's acquiescence

e. Sociodemographic profile of the patient population

f. History of intractability and failed treatment programs

2. Development and use of a staging system or multiaxial diagnosis or disability assessment tool may be able to assist in reflecting patient complexity

3. Clearer descriptions of the elements of the treatment program which predict outcome

a. Average length of stay and relationship to patient complexity and outcome

b. Better specification of multidisciplinary treatment, including nature of individualized and group psychological treatment

c. Headache diaries

d. Reliable and validated headache inventories and questionnaires

e. Measures reflecting functional performance, such as increased work effectiveness, return to work, and increased functioning at home

f. Valid assessments of comorbid psychological (eg, depression) and medical (eg, hypertension) conditions

g. Consideration of uniform outcome measure that can be applied by different 
programs. ${ }^{48,47}$ The use of standardized measures across different programs must, however, also take into account some description of patient complexity and acuity in order to compare results from one program to another.

4. Optimize research design

a. Prospective measures for single group outcome studies

b. Use of systematically staggered baseline designs (multiple baselines across patients) to reveal changes that occur only after treatment

c. Comparisons of inpatient versus specialized outpatient protocols for analgesic/abortive withdrawal in cases of analgesic rebound, possibly with random assignment of patients

d. Assessment of patient participation in and compliance with behavioral therapies, and relationship to treatment outcomes in multidisciplinary programs

5. Build an efficient, ongoing outcome evaluation system into ongoing clinical practice

6. Assessment of economic impact of $\mathrm{CH}$ in the population

a. Direct medical costs of $\mathrm{CH}$ including further analysis of the cost of acute treatments, preventive treatments, and rescue therapy such as emergency department utilization, alternative medicine costs, psychological and behavioral interventions, and hospital costs

b. Indirect cost of $\mathrm{CDH}$ including measures of lost work time, decreased productivity, impact on career choice and advancement, need for household help because of impact on housewives, impact on educational achievement and opportunities

c. Linkage of these economic assessments with treatment outcomes from hospitalization versus outpatient treatment

7. Assessment of the natural history and risk factors for progression of episodic headache disorders such as migraine or episodic tensiontype headache as a prelude to preventive intervention
Even with the investigation of the areas cited above for further research, there exist numerous obstacles to generating class I data. These obstacles include the ethics of placebo-controlled trials of any length of time in patients with a highly refractive and highly disabling state as has been characterized for patients currently being treated inpatient, controlling for different components of multidisciplinary treatment, and the funding of such studies.

Acknowledgments: The US Headache Guidelines Consortium Project and the National Headache Foundation supported the meeting. Members of the Consortium include: Harvey Blumenthal, MD; Roger Cady, MD; James Couch, MD; Seymour Diamond, MD; Frederick G. Freitag, DO; R. Michael Gallagher, DO; Al Lake, III, PhD; Richard Lipton, MD; Ninan Mathew, MD; Alan Rapoport, MD; Jay Rosenberg, MD; Joel Saper, MD; and Stephen Silberstein, MD.

\section{REFERENCES}

1. Saper JR. Daily chronic headache. Neurol Clin. 1990;8:891-901.

2. Solomon S, Lipton RB, Newman LC. Evaluation of chronic daily headache-comparison to criteria for chronic tension type headache. Cephalalgia. 1992;12:365-368.

3. Pfaffenrath V, Isler H. Evaluation of the nosology of chronic tension type headache. Cephalalgia. 1993;13(suppl 12):60-62.

4. Mathew NT. Transformed migraine. Cephalalgia. 1993;13(suppl 12):78-83.

5. Silberstein SD, Lipton RB, Sliwinski M. Classification of daily and near daily headaches: field trial of revised IHS criteria. Neurology. 1996;47:871-875.

6. Manzoni GC, Granella F, Sandrini G, Cavallini A, Zanferrari C, Nappi G. Classification of chronic daily headache by International Headache Society criteria: limits and new proposals. Cephalalgia. 1995;15:3743.

7. Sanin LC, Mathew NT, Bellmeyer LR, Ali S. The International Headache Society (IHS) headache classification as applied to a headache clinic population. Cephalalgia. 1994;14:443-446.

8. Lipton RB, Silberstein SD, Stewart WF. An update on the epidemiology of migraine. Headache. 1994;34: 319-328.

9. Rothrock J, Patel M, Lyden P, Jackson C. Demographic and clinical characteristics of patients with 
episodic migraine versus chronic daily headache. Cephalalgia. 1996;16:44-49.

10. Mathew NT, Reuveni U, Perez F. Transformed or evolutive migraine. Headache. 1987;27:102-106.

11. Mathew NT. Chronic daily headache: clinical features and natural history. In: Nappi G, ed. Headache and Depression: Serotonin Pathways as a Common Clue. New York: Raven Press; 1991.

12. Koenig MA, Gladstein J, McCarter RJ, Hershey AD, Wasiewski W. Chronic daily headache in children and adolescents presenting to tertiary headache clinics. Headache. 2002;42:491-500.

13. Sandrini G, Manzoni GC, Zanferrari C, Nappi G. An epidemiological approach to the nosology of chronic daily headache. Cephalalgia. 1993;13(suppl 12):7277.

14. Silberstein SD. Tension type and chronic daily headache. Neurology. 1993;43:1644-1649.

15. Mathew NT, Stubits E, Nigam MP. Transformation of episodic migraine into daily headache: analysis of factors. Headache. 1982;22:66-68.

16. Breslau N. Psychiatric comorbidity in migraine. Cephalalgia. 1998;18(suppl 22):56-61.

17. Kessler RC, Frank RG. The impact of psychiatric disorders on work loss days. Psychol Med. 1997;27:861873.

18. Clouse JC, Osterhaus JT. Healthcare resource use and costs associated with migraine in a managed healthcare setting. Pharmacoeconomics. 1994;28:659664.

19. Scher AI, Stewart WF, Liberman J, Lipton RB. Prevalence of frequent headache in a population sample. Headache. 1998;38:497-506.

20. National Bureau of Economic Research. Trends in the Well Being of American Women, 1970-1995. Cambridge, MA: National Bureau of Economic Research; 1998. NBER Working Paper 6206.

21. Rasmussen BK. Epidemiology of headache. Cephalalgia. 1995;15:45-68.

22. Lavados PM, Tenham E. Epidemiology of tension type headache in Santiago, Chile: a prevalence study. Cephalalgia. 1998;18:552-558.

23. Wong TW, Wong KS, Yu TS, Kay R. Prevalence of migraine and other headaches in Hong Kong. Neuroepidemiology. 1995;14:82-91.

24. Tekle Haimanot R, Seraw B, Forsgren L, Ekbom K, Ekstedt J. Migraine, chronic tension type headache, and cluster headache in an Ethiopian rural community. Cephalalgia. 1995;15:482-488.
25. Newman LC, Lipton RB, Stewart WF. Severe daily headaches in a population sample: results from the American Migraine Study [abstract]. Headache. 1994;34:295.

26. $\mathrm{Hu} \mathrm{XH}$, Markson LE, Lipton RB, et al. Burden of migraine in the United States: disability and economic costs. Arch Intern Med. 1999;159:813-818.

27. Osterhaus JT, Gutterman DL, Plachetka JR. Healthcare resource and lost labor costs of migraine headache in the US. Pharmacoeconomics. 1992;2:6776.

28. Fishman P, Black L. Indirect costs of migraine in a managed care population. Cephalalgia. 1999;19:5057.

29. Rome HP, Rome JD. Limbically augmented pain syndrome (LAPS): kindling, corticolimbic sensitization, and the convergence of affective and sensory symptoms in chronic pain disorders. Pain Med.2000;1:7-23.

30. Von Korff M, Ormel J, Keefe FJ, Dworkin SF. Grading the severity of chronic pain. Pain. 1992;50:133-149.

31. Von Korff M, Stewart WF, Simon DJ, Lipton RB. Migraine and reduced work performance: a population based diary study. Neurology. 1998;50:1741-1745.

32. Fishman P, Von Korff M, Lozano P, et al. Chronic care costs in managed care. Health Affairs. 1997;16:239247.

33. Cady R, Schreiber C. Pharmacoeconomics implication of migraine and migraine therapies. In press.

34. Villareal SS. A comparative study of selected patient variable risk factors in hospitalization for chronic headache. Headache. 1995;35:349-354.

35. Rapoport A, Stang P, Gutterman DL, et al. Analgesic rebound headache in clinical practice: data from a physician survey. Headache. 1996;36:14-19.

36. Saper JR, Silberstein S, Gordon CD, Hamel RL, Swidan S. Handbook of Headache Management. A Practical Guide To Diagnosis of Head, Neck and Facial Pain. 2nd ed. Philadelphia: Lippincott, Williams and Wilkins; 1999.

37. Freitag F, Cady R, eds. The National Headache Foundation Standards of Care. 3rd ed. National Headache Foundation, 2001.

38. Diamond S, Freitag FG, Maliszewski M. Inpatient treatment of headache: long-term results. Headache. 1986;26:189-197.

39. Lake AE III, Saper JR, Madden SF, Kreeger C. Comprehensive inpatient treatment for intractable migraine: a prospective long-term outcome study. Headache. 1993;33:55-62. 
40. Freitag FG. Headache clinics and inpatient treatment. In: Diamond ML, Solomon G, eds. Diamond and Dalessio's Practicing Physicians Approach to Headache. Baltimore: Williams and Wilkens, 1993.

41. American Academy of Neurology. Practice parameter: appropriate use of ergotamine tartrate and dihydroergotamine in the treatment of migraine and status migrainosus [summary statement]. Report of the Quality Standard Subcommittee of the American Academy of Neurology. Neurology. 1995;45:585-587.

42. Headache Classification Committee of the International Headache Society, Classification and diagnostic criteria for headache disorders, cranial neuralgias and facial pain. Cephalalgia. 1988;8(suppl 7):1-96.

43. Mathew NT, Kurman R, Perez F. Drug induced refractory headache-clinical features and management. Headache. 1990;30:634-638.

44. Dalessio DJ. The clonidine protocol. Headache $Q$. 1991;2:133-134.

45. Silberstein SD, McCrory DC. Butalbital in the treatment of headache: history, pharmacology and efficacy. Headache. 2001;41:953-967.

46. Guidetti V, Galli F, Fabrizi P, et al. Headache and psychiatric comorbidity: clinical aspects and outcome in an 8-year follow-up study. Cephalalgia. 1998;18:455462.

47. Smith R. Impact of migraine on the family. Headache. 1998;38:423-426.

48. Tfelt-Hansen P, Krabbe AA. Ergotamine abuse. Do patients benefit from withdrawal? Cephalalgia. 1981;1:29-32.

49. Ala-Hurula V, Myllylä V, Hokkanen E. Ergotamine abuse: results of ergotamine discontinuation, with special reference to the plasma concentrations. Cephalalgia. 1982;2:189-195.

50. Raskin NH. Repetitive intravenous dihydroergotamine as therapy for intractable migraine. Neurology. 1986;36:995-997.

51. Baumgartner C, Wessely P, Bingol C, Maly J, Holzner F. Long-term prognosis of analgesic withdrawal inpatients with drug induced headache. Headache. 1989;29:510-514.

52. Diener HC, Dichgans J, Scholz E, Geiselhart S, Gerber WD, Bille A. Analgesic-induced chronic headache: long-term results of withdrawal therapy. J Neurol. 1989;236:9-14.

53. Silberstein SD, Schulman EA, Hopkins MF. Repetitive intravenous DHE in the treatment of refractory headaches. Headache. 1990;30:334-339.
54. Silberstein SD, Silberstein JR. Chronic daily headache: long-term prognosis following inpatient treatment with repetitive IV DHE. Headache. 1992;32:439-445.

55. Schnider P, Maly J, Grunberger J, Aull S, Zeiler K, Wessely P. Improvement of decreased critical flicker frequency (CFF) in headache patients with drug abuse after successful withdrawal. Headache. 1995;35:269-272.

56. Schnider P, Auall S, Baumgartner C, et al. Long-term outcome of patients with headache and drug abuse after inpatient withdrawal: five-year follow-up. Cephalalgia. 1996;16:481-485.

57. Ford RG, Ford KT. Continuous intravenous dihydroergotamine in the treatment of intractable headache. Headache. 1997;37:129-136.

58. Pringsheim T, Howse D. In-patient treatment of chronic daily headache using dihydroergotamine: a long-term follow-up study. Can J Neurol Sci. 1998;25:146-150.

59. Monzón MJ, Láinez JM. Chronic daily headache: long-term prognosis following inpatient treatment. Headache Q. 1998;9:326-330.

60. Diamond S, Freitag FG, Prager J, Gandhi S. Treatment of intractable cluster. Headache. 1986;26:42-46.

61. Mather PJ, Silberstein SD, Schulman EA, Hopkins MM. The treatment of cluster headache with repetitive intravenous dihydroergotamine. Headache. 1991;31:525-532.

62. McBeath JG, Nanda A. Use of dihydroergotamine in patients with post-concussion syndrome. Headache. 1994;34:148-151.

63. Diamond S, Freitag FG, Maliszewski M, Prager J, Gandhi S. Treatment of headache in an inpatient headache unit: long-term results [abstract]. Cephalalgia. 1985;5(suppl 3):440-441.

64. Saper JR. Treatment of ergotamine dependency: techniques, outcome, and recidivism [abstract]. Headache. 1987;27:306.

65. Diamond S, Freitag FG, Solomon GD. Impact of inpatient headache treatment on subsequent medical care [abstract]. Headache. 1988;28:317.

66. Lake AE III, Saper JR. Prospective outcome evaluation of an accredited inpatient headache program [abstract]. Headache. 1988;28:315.

67. Wall DJ, Haugh MJ. Biofeedback as an adjunct to repetitive intravenous dihydroergotamine in the treatment of refractory headache [abstract]. Headache. 1993;33:285. 
68. Weeks RE, Baskin SM, Rapoport AM, Sheftell FD. A prospective analysis of repetitive intravenous DHE in the treatment of refractory headache [abstract]. Headache. 1993;33:286.

69. Saper JR, Lake AE III, Madden S, Kreeger C. Comprehensive inpatient treatment for intractable head pain: patient factors associated with outcome [abstract]. Headache. 1994;34:514.

70. Loughner BA, Dawson GA, Casaly JS. Inpatient treatment of chronic daily headache: outcome measures [abstract]. Headache. 1995;35:306.

71. Weeks RE, Baskin SM, Rapoport AM, Sheftell FD. In patient headache treatment: analysis of out come post-discharge. [abstract]. Neurology. 1995;45(suppl 4):A379.

72. Diamond S, Freitag FG, Diamond ML, Urban GJ. IV histamine therapy in intractable cluster headaches [abstract]. Cephalalgia. 1996;16:358-359.

73. Diamond S, Freitag FG, Bambhvani S. IV histamine desensitization therapy and recidivism: chronic cluster headache patients [abstract]. Cephalalgia. 1997;17:457.

74. YoungWB, Hopkins MM, Janyszek B, Primavera JP III. Repetitive intravenous DHE in the treatment of refractory post-traumatic headache [abstract]. Headache. 1994;34:297.

75. Robbins L, Remmes A. Outpatient repetitive intravenous dihydroergotamine. Headache. 1992;32:455458.
76. Robbins L. Intravenous DHE and cost saving [abstract]. Headache. 1995;35:50.

77. Drucker P, Tepper S. Repetitive outpatient oral sumatriptan for detoxification for patients with transformed migraine with medication overuse. Headache. 1997;37:307-308.

78. Suhr B, Evers S, Bauer B, Gralow I, Grotemeyer KH, Hussted IW. Drug-induced headache: long-term results of stationary versus ambulatory withdrawal therapy. Cephalalgia 1999;19:44-49.

79. Pini LA, Bigarelli M, Vitale G, Sternieri E. Headache associated with chronic use of analgesics: a therapeutic approach. Headache. 1996;36:433-439.

80. Casaly JS, Loughner BA, Chen M. Comparative impact of inpatient therapy versus exclusively outpatient management of highly disabled headache sufferers [abstract]. Headache. 1999;39:347-348.

81. de Williams AC, Richardson PH, Nicholas MK, et al. Inpatient versus outpatient pain management: results of a randomized controlled trial. Pain. 1996;66:13-22.

82. Hoodin F, Brines BJ, Lake III AE, Wilson J, Saper JR. Behavioral self-management in an inpatient headache treatment unit: increasing adherence and relationship to changes in affective distress. Headache. 2000;40:377-383.

83. Grazzi L, Andrasik F, D'Amico D, et al. Behavioral approach in the treatment of chronic daily headache with drug overuse: a 3-year follow-up study [abstract]. Cephalalgia. 2000;20:300. 